\title{
Green Logistics Practices and Firm Performance: The Mediating Effect of Economic Performance Among Logistics Firms in Kenya
}

\author{
Mutua Daniel Mutie, PhD Candidate \\ Dr. Stephen Odock, Senior Lecturer \\ Department of Management Science \\ School of Business, University of Nairobi, Kenya
}

Prof. Kate Litondo, Associate Professor

Department of Management Science

School of Business, University of Nairobi, Kenya

Doi:10.19044/esj.2020.v16n25p142 URL:http://dx.doi.org/10.19044/esj.2020.v16n25p142

\begin{abstract}
Emissions from the logistics industry are rising at a greater concern than any other industry and the trend is expected to continue such that by 2030 these levels will be $80 \%$ higher than they were in 2007 unless there is a change. Many firms aim at reducing cost and they need to strike a balance between economic, social and ecological factors for sustainability. This study establishes mediating role of economic performance on the relationship between green logistics practices and the performance of logistics firms operating in Kenya. The study is guided by the philosophy of positivism research and it applied the cross-sectional survey research design. The population of interest consist of 892 logistics firms in Kenya from which a sample of 300 firms is drawn. Primary data were collected using a structured questionnaire. Validity and reliability measurement were done using three frequently used methods - construct reliability (CR), average variance extracted (AVE), Cronbach's alpha. Data were analyzed using covariancebased structural equation modelling (CB-SEM). The study established that there is a significant positive relationship between the implementation of green logistics practices and firm performance of logistics firms in Kenya ( $\beta=0.63$, $p<0.001)$. The mediating effect of economic performance on the relationship between green logistics practices and firm performance was found to be positive and significant $(\beta=.020, p=.039)$ at 0.05 significance level. It is recommended that logistics firms in Kenya should implement environmentfriendly practices both within firms and in the wider supply chain.
\end{abstract}


Keywords: Green logistics practices; economic performance; firm performance

\section{Introduction}

Ecological concerns have become essential for organizations given the current context of globalization (Molina-Besch \& Pålsson 2014). Industrialization and consumerism are ever-growing bringing in a scenario where trade pursuit of humans has begun to spread unfavourable environmental impact (Ratnajeewa \& Bandara, 2015). The greater focus now is on ecological pollution through logistics practices. In the recent past, interest has shifted to the effects of logistics on climate change, owing to the improved understanding of the danger being posed by global warming (McKinnon, Cullinane, Browne \& Whiteing, 2010). Green logistics practice is the way to go as it consists of activities which are associated with the ecoefficient organization of the forward and reverse flows of information and products from the point of origin and the consumption point to meet or exceed customer expectations (Carter \& Easton, 2011).

The green logistics practices include green packaging, route optimization, fuel efficiency, carbon emission measurement and reverse logistics (McKinnon, Browne \& Whiteing, 2010; Molina-Besch \& Pålsson 2014; Hampus \& Henrik, 2015; Weng \& Chen, 2015). The practices were chosen because of the impact they have on the logistics sector and the capability of their logistics operations becoming greener. Green Packaging is the use of packaging optimization technique which is important for logistical organizations to reduce their environmental impact (Laosirihongthong, et. al., 2013). When organizations are implementing their environmental programs, it becomes important to reduce solid waste like metal scrap, materials, packaging and organic waste. Thirty-three per cent of the waste stream comes from packaging material, which indicates that it is important to have programs in green packaging to have the ability to decrease an organization's carbon footprint effectively (Isaksson \& Huge-Brodin, 2013).

A tool that can be friendly to the environment and efficient is using improved fuel-efficient fleets. Fuel efficiency can be enhanced by using proper maintenance programs, eco-driving techniques and alternative fuels. Logistics greenness can be increased by shifting to more efficient and ecofriendly fuels. Wu and Dunn (1995) identified safer, cleaner and more accessible alternative fuels compared to diesel, which consisted of liquefied natural gas (LNG) and compressed natural gas (CNG) which is cheaper than petrol by 40 per cent. Consequently, there ought to be a shift by logistics companies to the usage of alternative fuels if they want to have an environmentally sustainable future. 
Another way of improving fuel efficiency is by using an eco-driving technique which aims at reducing the consumption of fuel. Drivers are trained on how to save fuel without a loss in mobility. There is a possibility of saving up to 25 per cent of fuel consumption. Firms can monitor driving behaviours and fuel consumption of each truck using a tracking system which can inform them of unnecessary or excess usage of vehicles, unauthorized use of a private vehicle, driving behaviours which are poor, fuel wastage and drivers speeding and idling (Janota, Dado \& Spalek, 2010). Another major environmental issue is proper maintenance of the trucks in an efficient and safe condition which does not only extend the vehicle lifetime but also improves the efficiency of the vehicle and reduce the rate of accidents (Hampus \& Henrik, 2015).

Optimization of routes has to do with the coordination of a fleet of vehicles, which has a capacity that is fixed in the most possible efficient way, which gets a feasible solution that reduces the voyage amount, time travelled in total and the vehicle numbers in use to the minimum. Ecologically responsible logistics companies would have better space utilization, more direct routes, fewer shipments, less handling and shorter movements $(\mathrm{Wu} \&$ Dunn, 1995). The above issues lead to lower pollution levels because automobiles travel at the best efficient paces that are friendlier to the environment and consume less fuel. Therefore, optimization of routes is an expense reducer as a result of minimization of travelled distances and economical vehicle usage. According to Sbihi and Eglese (2010), organizations can achieve route optimization by making sure that vehicles heading to congested routes are redirected to faster and more efficient routes which many a time brings the implication that the suggested route leads to an increase of the length of total travel other than the use of a shorter route that is less efficient.

Logistics companies measure emissions, which come from their activities. Transportation actions produce the largest carbon dioxide emissions within the logistics industry (Wolf \& Seuring, 2010). If a company measures the logistics' chain emission, it can reduce the associated expenses and on the environmental impact by checking the areas of emission and unnecessary waste to reduce it. Hart and Ahuja (1996) argue that pollution prevention is the ability to not just reduce the company's overall effect on the environment, but also cost, enhancing overall efficiency and effectiveness of the firm. They continue to posit that by removing waste and optimizing operations logistics companies can prevent pollution. The conclusion they make is that there is a benefit of being green because it cuts down on cost and efficiency is increased. Though there is an initial investment required, it is advantageous in the long run to be ecologically friendly. When companies discover and analyze their logistics chains, they receive knowledge of areas they can achieve waste reductions and also areas of inefficiency. 
The reverse logistics concept is stated as the movement of material from the consumption point back to the original point. It is different from forward logistics which specifically refers to transport from the place of origin to the point of consumption (Rogers \& Tibben-Lembke, 2001). Therefore, the approach intends to utilize transports fully and decrease the number of empty return freights. They further stated that the vehicles making a return from the consumption point are involved in, reusable packaging, remanufacturing and recycling. This illustrates how the flow of goods and reverse logistics fits into the supply chain. A case in point would be using reverse logistics to recycle used and old computers, after delivering new model computers by use of forward logistics. Wu and Dunn (1995) argue that there is an increase in twoway freights and this can only increase into the future because of returnable and reusable packaging. They continue to posit that there is a need for supply chains to have the capacity to adapt to this increase and reverse logistics raises costs because of the extra storage and handling.

Firm performance is described as a comprehensive construct that can be unidimensional or multidimensional (Selvam, Gayathr, Vasanth, Lingaraja, \& Marxiaoli, 2016). It is argued to be a dependent variable influenced by multiple factors. Firm performance measurement is an integral part of ensuring firms continued success. Neely, Gregory and Platts, (1995) defined firm performance as a metric used to measure the effectiveness and efficiency of organizational action. There is a need for such metrics to directly relate to the firm's objectives and mission, imitate the firm's external competitive environment, internal objectives and customer requirements. The balanced scorecard (BSC), one of the most prominent measures of firm performance was developed as a structure that included non-financial performance to the traditional economic metrics to give a clear and holistic view of firm performance (Kaplan \& Norton, 2010).

The economic value and profits that a company makes is the economical factor in the TBL. Economical aspect is the conventional measurement instrument that is mostly used when assessing the performance of an organization. Costs for logistics and delivery reliability are additional economic indicators related to sustainable logistics (De Giovanni, 2012). When a logistics company cuts its costs, it impacts less on the environment, because there are lower levels of emissions (Hampus \& Henrik, 2014). This study used the definition of economic performance as suggested by Annika and Cheng (2018) where they argued that economic performance relates to the capability of a firm organization to cut down on costs related to materials purchased, energy consumed, fuel cost, waste treated, waste discharged, and fines due to environmental incidents and accidents. The relationship between green logistics practice and economic performance is anchored on the Triple Bottom Line (TBL) theory. Customers are more than willing to buy a product 
from a socially and ecologically conscious organization, which can give the company a competitive advantage (De Giovanni, 2012).

Eight per cent of the world's current total carbon emissions emanate from logistics and the environment is affected to a great extent (McKinnon, Cullinane, Browne, \& Whiteing, 2010). The World Trade Economic Forum (2009) affirmed that $5.5 \%$ of the total greenhouse emissions globally originate from logistics. This is inclusive of all types of greenhouse gases, not just carbon dioxide. Out of these, two-thirds can be linked to road-transports. Emissions from logistics industry are rising at a greater rate than any other industry and the trend is expected to continue such that by 2030 these levels will be 80 per cent greater than current levels unless there is a change (Ribeiro et al., 2007). In consideration of the above rates of emission emanating from the logistics industry, it is vital to initiate countering resolutions. One commonly talked about the method is the initiation of green logistics as a deed to reduce the environmental effect of transportation practices. Taking measures regarding environmental concerns in a socially responsible way is becoming an important part of the modern organization agenda (Murphy $\&$ Poist, 2003). Firms aim to reduce cost and they need to strike a balance between economic, social and ecological factors for sustainability.

The National Climate Change Action Plan (NCCAP) investigation submits that GHG emissions in Kenya will upsurge in all sectors until 2030 with transport emissions increasing the most by a factor of three. The discovery of coal and oil deposits, which are commercially viable, will most probably contribute to increased emissions in Kenya. Traffic congestion in major towns and cities, specifically during peak hours, increases local air pollution and contributes to GHG emissions through the use of more fossil fuel, which have severe health implications (NCCFP, 2016). Organizations in developing countries are still learning how to integrate green practices in their day-to-day operations compared to those in developed countries (Rao, 2007). Many firms in Kenya have not fully understood the impact of environmental management specifically in the logistics sector.

\section{Literature review}

This research is grounded on the following theories: resource-based view and the natural resource-based view. Wernerfelt (1984) developed the RBV which proposes that an organization's performance and competitive strategy depend significantly on its rare, non-substitutable, inimitable and valuable resources. A rare resource is one, which is not accessible to many firms. The degree to which resources are line up with the external environment to minimize threats and to exploit opportunities is referred to as value. The non-substitutability quality is usually the degree to which competitors are unable to create similar resources. Hoskisson, Hitt, Wan, and Yiu (1999) 
defined inimitable as the degree to which opponents cannot replicate or acquire the resources, or can only do so at a substantial cost.

The natural resource-based view (NRBV) is an extension of the RBV and is used extensively in the explanation of the reason why firms take up green initiatives. It is, therefore, the main theory for this study. The NRBV argues that competitive advantage and strategy can be fashioned from capabilities facilitating economic activities, which are environmentally sustainable (Hart, 1995). Hart posits that for a resource to be rare, valuable, non-substitutable and inimitable, it has to be firm-specific, socially complex and causally ambiguous. The inimitability of an organization's strategic resource gives the firm protective machinery from the acquisition of similar resources by competitors. The reason for this is that such resources are causally ambiguous as they are established over a duration of time through continuous experience and learning. The social complexity of the resource is attained through highly synchronized activities involving many people and teams that means, the overall phenomenon can only be adequately understood by a few individuals (Barney, 1991). Green logistics practices are resources that are firm-specific, socially complex and causally ambiguous and therefore meeting the definition in the NRBV.

Emissions from logistics industry are rising at a greater concern than any other industry and the trend is expected to continue such that by 2030 these levels will be $80 \%$ higher than present levels unless there is a change (Ribeiro, et. al., 2007). In consideration of the above rates of emission emanating from the logistics industry, it is vital to initiate countering resolutions. One commonly talked about the method is the initiation of green logistics as a measure to reduce the environmental effect of transportation practices. Taking measures regarding environmental concerns in a socially responsible way is becoming an important part of the modern organization agenda (Murphy \& Poist, 2003). Firms aim to reduce cost and they need to strike a balance between economic, social and ecological factors for sustainability.

Several empirical studies have been carried out to investigate the relationship between green initiatives and firm performance.(Donghyun, Sang \& Sung, 2012; Lai \& Wong, 2012; Isaksson, 2012; Kung, Huang \& Cheng, 2013; Laosirihongthong, Adebanjo \& Tan, 2013; Björklund \& Forslund, 2014; Weng \& Chen, 2015; Mogeni \& Kiarie, 2016). However, some studies have indicated a positive link between green logistics practices and firm performance (Kung, Huang \& Cheng, 2013; Björklund \& Forslund, 2014; Weng \& Chen, 2015). Others have indicated no link between particular green logistics practices and firm performance (Donghyun, Sang \& Sung, 2012; Isaksson, 2012). While some established the existence of a negative association between specific green logistics practices and firm performance 
(Cordeiro \& Sarkis, 1997). To add on that, others found a blend of positive and other relationships (Laosirihongthong, Adebanjo, \& Tan, 2013).

Savitz and Weber (2006) indicate that the conventional monetary assessment tools such as profit, return on investment (ROI), sales, financial flows and taxes paid, determine the economical factor. Labour exploitation in a country where costs are low and also of the low standard would be a case of an economically driven but unsustainable organization. In road transportation, firms can cut costs and enhance economic performance by fuel or route optimization and reverse logistics. On the other hand, when a logistics company cuts its costs, it impacts less on the environment, as there is a lower emissions level. The proposition for this research is that economic performance has a positive impact on firm performance. It has also been determined that economic performance can also be enhanced by implementing green logistics practices (Zhu \& Sarkis, 2004; Rao \& Holt, 2007; Green et al., 2012). It is also expected that economic performance is positively related to firm performance (Sibel \& Bulent, 2019). This leads to the following proposition: The relationship between green logistics practices and firm's performance is mediated by economic performance.

\section{Conceptual Framework}

The study developed the conceptual model as indicated in Figure 1 to explain the relationship between the variables under investigation. In this case, green logistics practice is the independent variable measured by reverse logistic, fuel efficiency, carbon emissions management, green packaging and optimization of routes. Economic performance is the mediating variable whose indicators are cost-cutting on; Material purchased, Environmental accident fines, waste treated, energy consumption bills. On the other hand, firm performance is the dependent variable of the study estimated based on financial perspective, customer perspective, internal processes perspective, as well as learning and growth perspective. 
Figure 1: Conceptual Framework

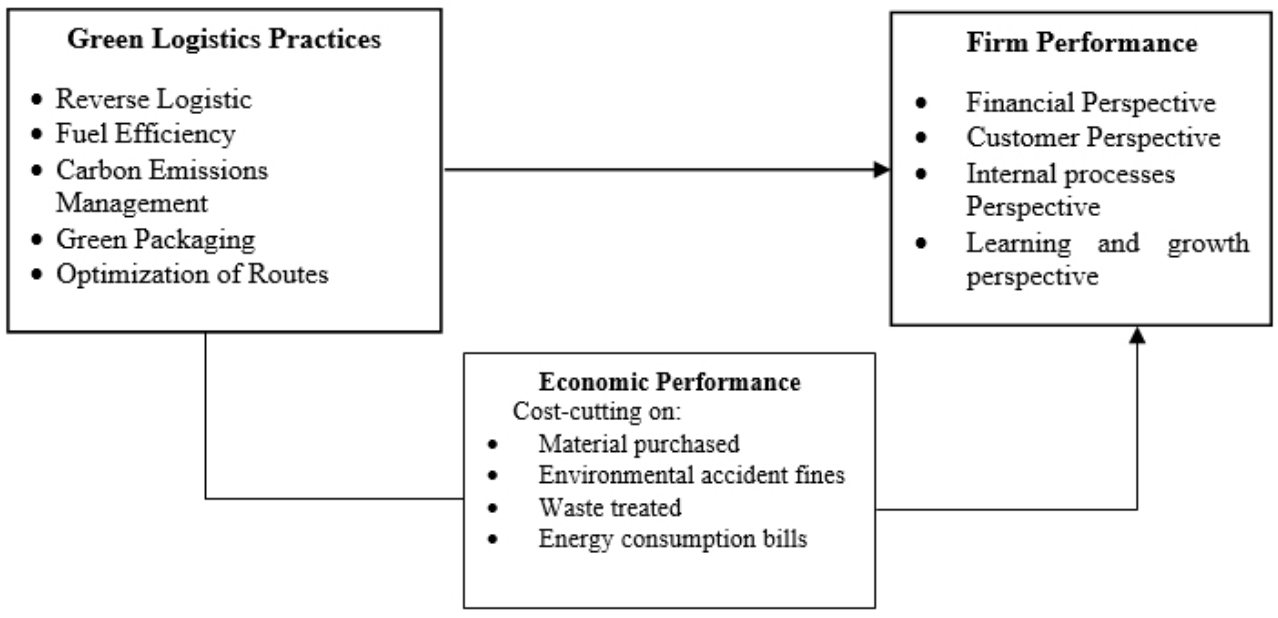

Source: Research Data (2020)

\section{Materials and Methods}

Positivist research philosophy is what guided the current study because it involved objective testing of hypotheses formulated as predictions of theory and conceptual model. The study aimed to objectively collect data and the researcher was independent of the study. It was a deductive study aimed at generalizing its findings which were quantifiable and observable. Given the aforementioned characteristics of this study, positivist philosophy was the most suitable philosophy to be adopted by this research.

The cross-sectional survey research design was employed. The population of interest consisted of all the 892 logistics firms in Kenya which were registered under Kenya International Freight and Warehousing Association (KIFWA) which was a representation of all Kenyan logistics firms (KIFWA, 2018). Out the total study's population, a sample size of 300 was drawn from which primary data was collected using a structured questionnaire. The sample size is determined using the Slovin's formula. Ariola (2006) suggests that in using Slovin's formula, the error of tolerance is between 0.05 and 0.01 . This study will use 0.05 as a tolerance error. Data were analyzed using covariance-based structural equation modelling (CB-SEM) of which Analysis of Moment Structures (AMOS) software was used in the analysis. The study assumed that hypothesis would be supported if Normed chi-square is between 1 and 3, Comparative Fit Index (CFI) value is greater than 0.95, Standardized Root Mean Square Residual (SRMR) is less than 0.08, Root Mean Square Error of Approximation (RMSEA) is less than 0.06 and $p$ values of path coefficient is less than 0.05 .

The questionnaires were sent to a total of 300 logistics firms and 233 questionnaires were received back. A total of 67 firms did not respond or 
declined to participate with some citing to have a "no-survey" policy. There were also monitoring difficulties because of geographical distance. Some firms were unavailable to respond while others flatly refused to respond to the questionnaire. This resulted in a response rate of $77.67 \%$. This number was considered sufficient for SEM with nine constructs, as per the recommendation by Hair et al. (2010) no commonalities were lower than 0.45 . It was established that observed variables had KMO Measures of Sampling Adequacy of 0.797, that is greater than the threshold of 0.6 (Kaiser, 1974), pvalues for Barlett's test of Sphericity was less than 0.05 (Bartlett, 1954). Communalities were also found to be well above 0.3 showing that the selected variables were adequately correlated for factor analysis. All construct items are adequately normally distributed with kurtosis and skewness coefficients within the range of -3.00 and +3.00 . Additionally, the Shapiro-Wilk test was used to check the normality assumption all values were above 0.05 meaning that the research variables were normally distributed. The Cronbach's Alpha values reported were above the cutoff point of 0.7 . As shown in Table 1, all the factors were reflective because their indicators were largely interchangeable and highly correlated (Mackenzie, Podsakoff, \& Jarvis, 2005).

Table 1. Results of Cronbach's Alpha Reliability Test

\begin{tabular}{lcc}
\hline Factor Label & Cronbach's Alpha & Specification \\
\hline Green packaging practices & 0.913 & Reflective \\
Fuel efficiency practices & 0.864 & Reflective \\
Optimization of routes practices & 0.907 & Reflective \\
Carbon emission measurement & 0.919 & Reflective \\
Reverse logistics practices & 0.934 & Reflective \\
Economic performance & 0.891 & Reflective \\
Firm performance & 0.931 & Reflective \\
\hline
\end{tabular}

Source: Research Data (2020)

Multicollinearity was tested by computing VIF and its reciprocal, the tolerance. In this research, tolerance ranged from 0.354 to 0.653 and therefore it's reciprocal, VIF was between one and two, way below the threshold. This ensured that there was no possibility of data collinearity (Hair et al. 1995). An assumption is made that the residual value for any observation must be uncorrelated (independent). This assumption was checked using the DurbinWatson test, as it checks for autocorrelations which may exist among residuals. A value of 2.0 indicates no autocorrelation. Heteroskedasticity was tested using a scatter plot which can show the variance of statistical dispersion. The shape formed a pattern-less mist of dots suggesting that the heteroskedasticity assumption was met. All factors demonstrated satisfactory discriminant validity as the correlation matrix indicates no correlation higher than 0.70 as shown in Table 2. 
Table 2. Factor Correlation Matrix

\begin{tabular}{llllllll}
\hline Factor & RL & ORs & FP & CE & ECP & GP & FE \\
\hline RL & 1.000 & .330 & .403 & .391 & .625 & .406 & .239 \\
ORs & .330 & 1.000 & .441 & .331 & .353 & .461 & .253 \\
FP & .403 & .441 & 1.000 & .409 & .520 & .369 & .148 \\
CE & .391 & .331 & .409 & 1.000 & .344 & .244 & -.039 \\
ECP & .625 & .353 & .520 & .344 & 1.000 & .350 & .347 \\
GP & .406 & .461 & .369 & .244 & .350 & 1.000 & .280 \\
FE & .239 & .253 & .148 & -.039 & .347 & .280 & 1.000 \\
\hline
\end{tabular}

Source: Research Data (2020)

Extraction Method: Maximum Likelihood.

Rotation Method: Promax with Kaiser Normalization.

KEY

RL-Reverse logistics CE-Carbon Emission Measurement GP-Green Packaging

ORs-Optimization of Routes ECP- Economic Performance FE-Fuel Efficiency

FP-Firm Performance

To assess the reliability and validity of the model, Gaskin and Lim (2016), "Master Validity Tool", AMOS Plugin was used. There should be no convergent validity issues if the latent factors are to be well explained by its observed variable. The following thresholds should be met to ensure the reliability and validity are attained with these parameters; Composite Reliability (CR), Average Variance Extracted (AVE), Maximum Shared Variance (MSV) and Average Shared Variance (ASV). For reliability to be achieved, CR>0.70. To achieve convergent reliability, CR>AVE and AVE $>0.50$ (Hair, Black, \& Babin, 2010). For Discriminant validity to be achieved, MSV<AVE. For convergent validity, AVE was calculated. AVE greater than 0.50 was achieved for all the items meaning that convergent validity was achieved for all EFA extracted factors. To assess discriminant validity the square roots of AVE was compared (on the diagonal) to all inter-factor correlation as shown in Table 3. Adequate discriminant validity was exhibited by all factors since diagonal values were higher than the correlations. From the analysis, all the parameters had CR above the minimum threshold of 0.70 indicating sufficient composite validity. This showed that the variables retained during model modification process attained reliability and validity and therefore appropriate for use in the subsequent analysis. 
Table 3. Composite Reliability, Convergent and Discriminant Validity Results of the CFA Model

\begin{tabular}{cccccccccccc}
\hline & CR & AVE & MSV & MaxR(H) & FE & RL & ORt & FP & CE & ECP & GP \\
\hline FE & 0.833 & 0.627 & 0.423 & 0.853 & $\mathbf{0 . 7 9 2}$ & & & & & & \\
RL & 0.909 & 0.668 & 0.590 & 0.916 & 0.190 & $\mathbf{0 . 8 1 7}$ & & & & & \\
ORt & 0.908 & 0.711 & 0.471 & 0.914 & 0.475 & 0.596 & $\mathbf{0 . 8 4 3}$ & & & & \\
FP & 0.773 & 0.541 & 0.501 & 0.880 & 0.569 & 0.476 & 0.548 & $\mathbf{0 . 7 3 6}$ & & & \\
CE & 0.923 & 0.751 & 0.590 & 0.977 & 0.161 & 0.768 & 0.686 & 0.410 & $\mathbf{0 . 8 6 7}$ & & \\
ECP & 0.890 & 0.669 & 0.610 & 0.901 & 0.330 & 0.028 & 0.395 & 0.248 & 0.125 & $\mathbf{0 . 8 1 8}$ & \\
GP & 0.883 & 0.717 & 0.477 & 0.917 & 0.425 & 0.691 & 0.531 & 0.358 & 0.588 & 0.162 & $\mathbf{0 . 8 4 7}$ \\
\hline
\end{tabular}

Source: Research Data (2020)

References Significance iof iCorrelations: †ip $<\mathrm{i} 0.100, * \mathrm{p} \mathrm{i}<\mathrm{i} 0.050 * * \mathrm{p} \mathrm{i}<\mathrm{i} 0.010, * * * \mathrm{ip}<$ i0.001

Notes: The diagonal values show the square roots of AVE.

$\begin{array}{lll}\text { KEY } & \text { FP-Firm Performance } & \text { GP- Green Packaging } \\ \text { FE- Fuel Efficiency } & \text { CE- Carbon Emission Measurement } & \\ \text { ORt-Optimization of Routes } & \text { ECP- Economic Performance } & \text { RL- Reverse Logistics }\end{array}$

Harman's one-factor test was utilized to examine common method bias. The result shows that a single factor contributed $29.016 \%$ (i.e. $<50 \%$ ) of the total variance, implying the non-existence of a sole dominant factor. Hence, the Common Method Variance (CMV) bias in the dataset was not significant (Delerue \& Lejeune, 2010). Standard regression weights were compared before and after adding Common Latent Factor (CLF) and shows the model was not affected by the CLF meaning any of the deltas of the variables were more than 0.200 (Aiken \& West, 1991). Therefore the model did not need to be adjusted to include the common latent factor.

\section{Results}

Measurement model goodness-of-fit indices are as follows: $\chi^{2} / \mathrm{df}=2.981, \mathrm{CFI}=0.922, \mathrm{SRMR}=0.054$ and RMSEA $=0.067$. The normed chisquare test result was significant indicating that the model fitted well with the dataset. A CFI value close to 1 implies a good fit and index value above 0.90 is considered as sufficient (Gaskin \& Lim, 2016). All the parameter estimates magnitudes were positive and above the threshold value of 0.50 and therefore consistent with literature and theory. They all had a critical ratio above 2.00, therefore supporting the presence of unidimensionality of the constructs.

The hypothesis predicted that economic performance mediates the connection between green logistics and firm performance. To test the hypothesis, CB-SEM analysis was conducted. The results from testing this relationship are presented in Figure 2 and Table 4 . To investigate the mediating influence of economic performance on the link between green logistics practices and firm performance, Gaskin's AMOS Estimand was used. As demonstrated in Figure 2 the presence of a mediating influence of 
economic performance on the connection between green logistics practices and firm performance was checked. Sufficient structural model fit indices were obtained, that is, $\chi^{2} /$ d.f. $=1.762, \mathrm{CFI}=0.990$, SRMR $=0.037$, RMSEA $=$ 0.060 , PCLOSE $=0.285$.

The endogenous latent construct; firm performance has a coefficient of determination $\left(\mathrm{R}^{2}\right)$ of 0.447 , meaning that, the latent construct green logistics practices and economic performance construct explain $44.7 \%$ of the variance in firm performance. The relationship between green logistics practices and firm performance was positive and significant $(\beta=0.63$, $p<0.001$ ), bootstrapping results revealed that economic performance mediates the positive connection between green logistics practices and firm performance $(\beta=.020, p=.039)$ at 0.05 significance level. The hypothesis is supported as per the results presented in Table 4.

Figure 2: Mediation of Economic Performance on Green Logistics Practices and Firm Performance

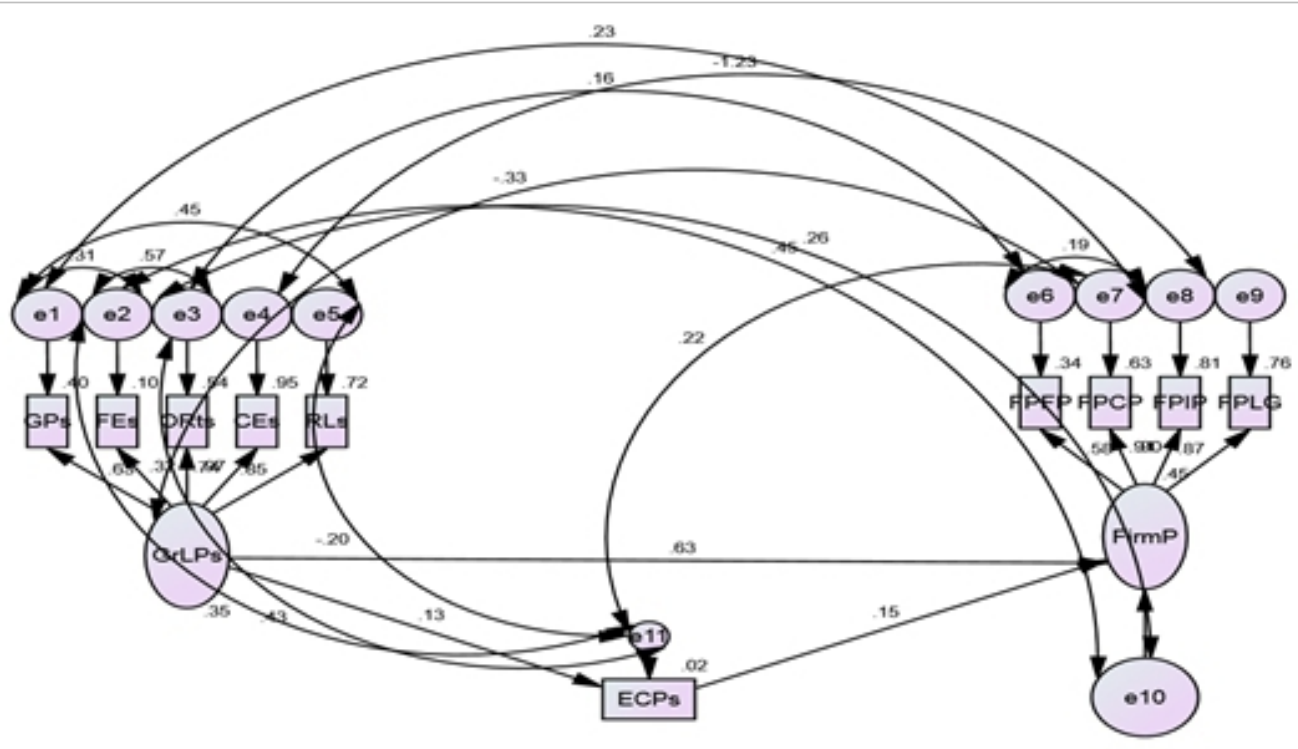

Source: Research Data (2020)

GPs= Exogenous latent construct (Green Packaging Practices)

FEs= Exogenous latent construct (Fuel Efficiency)

ORts= Exogenous latent construct (Optimization of Routes)

$\mathrm{CEs}=$ Exogenous latent construct (Carbon Emission)

$\mathrm{RLs}=$ Exogenous latent construct (Reverse Logistics)

GrLPs= Exogenous second-order latent construct

(Green Logistics Practices)

ECPs $=$ Mediating variables (Economic Performance)

FirmP= Endogenous latent construct (Firm Performance)

FPFP-Firm Performance Financial Perspective

FPCP- Firm Performance Customer Perspective

FPIP- Firm Performance Internal Processes

FPLG-Firm Performance Learning and Growth 
Table 4. Mediation of Economic Performance on Green Logistics Practices and Firm Performance

\begin{tabular}{|c|c|c|c|c|c|c|}
\hline $\begin{array}{l}\text { Dependent } \\
\text { Variable. }\end{array}$ & Parameter & Estimate & Lower & Upper & $\begin{array}{l}\text { P- } \\
\text { Value }\end{array}$ & $\begin{array}{l}\text { Hypothesis } \\
\text { testing result }\end{array}$ \\
\hline $\begin{array}{l}\text { Firm } \\
\text { Performance } \\
R^{2}=0.447\end{array}$ & $\begin{array}{l}\text { Green logistics } \\
\text { practices X } \\
\text { Economic } \\
\text { performance }\end{array}$ & .020 & .002 & .055 & .039 & Significant \\
\hline
\end{tabular}

Source: Research Data (2020)

\section{Discussion}

The findings have shown that green logistics practices significantly influenced firm performance positively since the significance level was less than 0.05 . The findings of the study have therefore indicated that green logistics practices, when adopted by a firm, could lead to better performance within logistics firms in Kenya. The study findings are in concurrence with conclusions from other previous studies (Lai \& Wong, 2012; Abareshi \& Molla, 2013). The findings support the NRBV and RBV, which provided theoretical anchorage to this relationship. The study consequently extends the literature by contributing to the positive link between green logistics practices and firm performance, therefore, reducing the uncertainty of contradictory findings from past studies on whether pursuing these practices is beneficial.

Sibel and Bulent (2019) found a positive linkage between economic performance and firm performance. The current study results support this position, in that, economic performance was found to have a significant and positive influence on firm performance. The mediating effect of economic performance on the link between green logistics practices and firm performance was established to be significant and positive. An explanation of this could be the one given by Kung, Huang, \& Cheng, (2013), when companies invest in green logistics practices, they can reduce investments on inventory, contain costs, and increase recovery of assets and result to improved firm performance.

\section{Summary and Conclusion}

The study observed that implementation of green logistics practices creates improvement in economic performance and this leads to improved firm performance. This is in line with the literature (Green et al., 2012, Sibel \& Bulent, 2019) The results support the views of resourced based view and the natural resourced based view confirming that green logistics practices do affect firm performance. Therefore, the study contributes to knowledge by ascertaining that economic performance is enhanced by implementing green logistics practices. This, in turn, improves firm performance (Rao \& Holt, 2007, Green et al., 2012) This indicates that achievement of firm performance 
is dependent on enhancing economic performance even from green logistics practices.

\section{Implication}

The chief input to knowledge by this research is that, although several researchers have claimed the firm performance benefits that accrue from green-related practices, only a few studies have empirically studied the performance effects of green logistics practices. Therefore, through theoretical explanation and empirical assessment, the study contributes to greater clarity and a better understanding of the linkages between green logistics practices and firm performance with the mediation of economic performance. The research adds to the existing literature by looking at economic performance as a mediating variable. This is consistent with recommendations of past researchers (Green et al., 2012; Lee et al., 2012) on the need to explore mediating variables that could help bring out the link between green practices and firm performance more fully. The findings provide that economic performance play a mediating role in the associations between the execution of green logistics practices and firm performance.

The current study provides useful information to policymakers. From a government standpoint, motivating organizations to go green is a smart choice given that green logistics practices have a positive effect on firm performance and will, therefore, contributes to economic growth and development. Policymakers must provide mechanisms that support firms as they implement green logistics practices. The research found that an increase in the level of enactment of green logistics practices is accompanied by an increase in performance. This conclusion effectively helps dismiss doubts of those firms that have not yet implemented green logistics practices. The results of this study will be of specific interest to industry regulators and government agencies that can provide information on green logistics practices and aid in the implementation of the same to improve Kenyan firms' capabilities.

\section{Limitations and suggestion for further research}

This study has limitations; this cross-sectional study is limited logistics firms in Kenya of the 892 companies who were members of KIFWA in 2018. Therefore, firms that were not members of KIFWA were not included in the sampling frame thought they might have had green logistics practices in their operations. Therefore, the results may lack robust external validity. For the generalizability of the research to increase, other firms who may not be KIFWA members and probably in other countries should be studied.

This research was a cross-sectional study using a quantitative approach that captured the perception of one respondent per organization at a specific point in time. Though this approach is effective in gathering the perception 
about the changing aspects of performance at a precise point in time, green logistics practices, economic and firm performance, fluctuate in a way that longitudinal studies lead to better and diverse perceptions. The data may have been affected by the respondents' inclination of any occasions that might have occurred previously or circumstances at the point of filling in the research instrument. Hence, the findings of the current research may differ from a longterm outlook. Therefore, a longitudinal study ought to be carried out to further authenticate the findings.

\section{Recommendations}

The study concluded that logistics firms in Kenya have implemented and put into operations practices of green logistics. This has played a critical role in influencing the overall performance of logistics firms in Kenya. The study further concluded that green logistics practices relate positively to economic performance in enhancing firm performance. These results have supported the concepts of resourced based view and the natural resourced based view, confirming that green logistics practices do affect firm performance.

This study has established that implementing green logistics practices leads to enhanced firm performance. It, therefore, recommends that logistics firms in Kenya should implement eco-friendly practices in all phases of their operations and the larger supply chain, beginning with practices like green packaging, fuel efficiency, optimization of routes, carbon emission measurement and reverse logistics. The study further suggests that the implementation of green logistics practices should be advocated to ensure the sustainability of not only the current generation but also the future generation. This is because operations of the logistics industry are the most widely recognized to affect the natural environment in the greatest negative way.

\section{References:}

1. Abareshi, A. \& Molla, A. (2013). Greening logistics and its impact on environmental performance: An absorptive capacity perspective. International Journal of Logistics. 16.

2. Aiken, L. S., \& West, S. G. (1991). Multiple regression: Testing and interpreting interactions. Sage Publications, Inc.

3. Annika, E., \& Cheng, G. (2018). Internal Green Supply Chain Management Practices Influence on Firm Performance. European Journal of Business and Management, 10(33), 23 - 29

4. Ariola, M. (2006). Principles and Methods of Research. Rex Bookstore Inc., Sampaloc. 
5. Bartlett, M. S. (1954). A note on multiplying factors for various chisquared approximations. Journal of the Royal Statistical Society, Series B 16, 296-298

6. Barney, J. (1991). Firm Resources and Sustained Competitive Advantage. Journal of Management, 17, 99-120.

7. Björklund, M., \& Forslund, H. (2014). The Shades of Green in Retail Chains' Logistics" In Sustainable Logistics. Published online: 4(1), 83-112.

8. Carter, C. \& Easton, P. (2011). Sustainable supply chain management: evolution and future directions. International Journal of Physical Distribution and Logistics Management, 41(1), 46 - 62.

9. Cordeiro, J., \& Sarkis, J. (1997). Environmental proactivism and firm performance: evidence from security analyst earnings forecasts. Business strategy and the Environment, 6(2), 104-114.

10. De Giovanni, P. (2012). Do External and Internal Environmental Management Contribute to the Triple Bottom Line? International Journal of Operations \& Production Management, 32(3), 265 - 290.

11. Donghyun, C., Sang, M., Sung, T., \& (2012). Green supply chain management and organizational performance, International Journal of Operations \& Production Management, 112(8), 1148 - 1180

12. Gaskin, J. \& Lim, J. (2016). Master Validity Tool, AMOS Plugin. Gaskination's StatWiki

13. Green, K., Zelbst, P., Meacham, J., \& Bhadauria, V. (2012). Green supply chain management practices: impact on performance. Supply Chain Management: An International Journal, 17(3), 290 - 305.

14. Hampus, G., \& Henrik S. (2015). Green Logistics in South Africa: A study of the managerial perceptions in the road transportation industry in South Africa (Unpublished Doctoral Thesis). Umea University, South Africa.

15. Hart, S. L. (1995). A natural-resource-based view of the firm. Academy of Management Review, 20(4), 986-1014.

16. Isaksson, K., \& Huge-Brodin, M. (2013). Understanding efficiencies behind logistics service providers' green offerings. Management Research Review, 36(3), 216 - 238.

17. Janota, A., Dado, M. \& Spalek J. (2010). Greening Dimension of Intelligent Transport. Journal of Green Engineering 2(3), 55-66.

18. MacKenzie, S. B., Podsakoff, P. M., \& Jarvis, C. B. (2005). The Problem of Measurement Model Misspecification in Behavioral and Organizational Research and Some Recommended Solutions. Journal of Applied Psychology, 90(4), 710-730.

19. Kaiser, H. F. (1974). An index of factorial simplicity. Psychometrika, 39(1), 31-36. 
20. Kaplan, R. S., \& Norton, D. P. (2010). The Strategy-Focused Organization: How Balanced Scorecard Companies Thrive in the New Competitive Environment, Boston: HBS Press.

21. Kenya International Freight and Warehousing Association (2018). Asia's leading business and networking platform for railway industry Nairobi, Kenya: KIFWA https://www.kifwa.co.ke/

22. Kung, F. H., Huang, C. L., \& Cheng, C. L. (2012). Assessing the green value chain to improve environmental performance: Evidence from Taiwan's manufacturing industry. International Journal of Development Issues, 11(2), 111-128.

23. Lai, F., Li, D., Wang, Q., \& Zhao, X.F. (2008). The information technology capability of third-party logistics providers: A resourcebased view and empirical evidence from China. Journal of Supply Chain Management, 44(3), 22-38.

24. Lee, P., Lau, A., \& Cheng, T. (2013). Employee Rights Protection and Financial Performance. J. Bus. Res. 66(1), 1861-1869.

25. Laosirihongthong, T., Adebanjo, D., \& Tan, K. (2013). Green supply chain management practices and performance. Industrial Management and Data Systems, 113(8), 1088 - 1109.

26. McKinnon, A. C., Cullinane, S., Browne, M., \& Whiteing, A. (2010). Green Logistics: Improving the Environmental Sustainability of Logistics. London: Kogan Page Series.

27. Mogeni, L \& Kiarie, D, (2016). Effect of Green Logistics Practices on Performance of Supply Chains in Multinational Organizations in Kenya. Industrial engineering journal 6(4), 40-50.

28. Molina-Besch, K., \& Pålsson, H. (2014). Packaging for Eco-Efficient Supply Chains: Why Logistics Should Get Involved in the Packaging Development Process. Journal of Sustainable Logistics, 1 (2), 137163.

29. Murphy, P. R., \& Poist, R. F. (2003). Green logistics strategies: An analysis of usage patterns. Transportation Journal, 5, 1-6.

30. Neely, A., Gregory, M. \& Platts, K. (1995). Performance measurement system design: A literature review and research agenda. International Journal of Operations \& Production Management, 15 (4), 80-116

31. Rao, P., \& Holt, D. (2007). Do green supply chains lead to competitiveness and economic performance? International Journal of Operations \& Production Management, 25(9), 898 - 916.

32. Ratnajeewa D. R., \& Bandara J. M. (2015). A Review of Research on Green Logistics Distribution Practices, The eighth International Research Conference. General Sir John Kotelwala Defence University. Review, 20(4), 986-1014. 
33. Ribeiro, K. S., Kobayashi, S., Beuthe, M., Gasca, J., Greene, D. Zhou, P. J. (2007). Transports and its Infrastructure. Press, C. U.

34. Rogers, D.S., \& Tibben-Lembke, R. (2001). An Examination of Environmental Performance Practices. Journal of Business Logistics, $22(2), 129-148$.

35. Savitz, A. W., \& Weber, K. (2006). The Triple Bottom Line: How Today's Best-run Companies are Achieving Economic, Social, and Environmental Success- and how you can too. $\left(1^{\text {st }} \mathrm{Ed}\right)$, San Francisco: Jossey-Bass Press.

36. Sbihi, A. \& Eglese, R. W. (2010). Combinatorial optimization and Green Logistics. Annals of Operations Research 17(5), 254 - 5330.

37. Selvam, M., Gayathri, J., Vasanth, V., Lingaraja, K., \& Marxiaoli, S. (2016) Determinants of Firm Performance: A Subjective Model, International Journal of Social Science Studies, 4(7), 134-148

38. Sibel, Y. C., \& Bulent S, (2019). Effects of green supply chain management practices on sustainability performance, Journal of Manufacturing Technology Management, 3(1), 98-121

39. Weng, H. \& Chen, J. (2015). Effects of Green Innovation on Environmental and Corporate Performance: A Stakeholder Perspective. Sustainability, 7, 4997-5026.

40. Wernerfelt, B. (1984). A Resource-Based View of the Firm. Strategic Management Journal, 5(2) 171-180.

41. Wolf \& Seuring, (2010). Environmental impacts as buying criteria for third party logistical services. International Journal of Physical Distribution \& Logistics Management, 40(1), 84-102.

42. Wu, H. J., \& Dunn, S. C. (1995). Environmentally responsible logistics systems. International Journal of Physical Distribution \& Logistics Management, 25(2), 20-38.

43. Zhu, Q., \& Sarkis, J. (2004). Relationships between operational practices and performance among early adopters of green supply chain management practices in Chinese manufacturing enterprises. Journal of Operations Management, 22(3), 265-289. 